\title{
Research Paper: Religious Coping Styles, General Health, and Psychological Well-Being Among Mothers of Mentally crossurk Disabled Children
}

\author{
Zahra Nikmanesh $^{1^{*}}$, Hadi Ansari² \\ 1. Department of Psychology, Faculty of Education and Psychology, University of Sistan and Baluchestan, Zahedan, Iran. \\ 2. Organization of Education, Zehak, Iran.
}

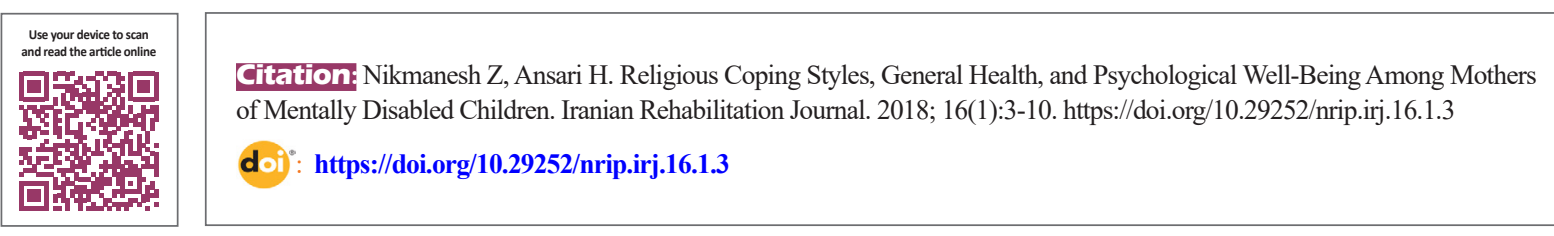

Article info:

Received: 22 Jul. 2017

Accepted: 16 Nov. 2017

\section{Keywords:}

Psychological, Religion, Health, Mentally disabled, Mothers

\begin{abstract}
Objectives: The birth and presence of an exceptional child in a family can be considered as an undesirable challenging event. This event may be associated with stress, frustration, sadness, and despair. This study aimed to examine the relationship of religious coping styles with general health and psychological well-being among mothers of mentally disabled children.
\end{abstract}

Methods: This cross-sectional study was conducted in the mothers $(n=68)$ whose mentally disabled children were enrolled in spacial schools in Zabol in the academic year 2012-2013. A study population was selected and homogenized through applying a convenience sampling method. Aflakseir and Coleman Religious Coping Scale, Keyes and Magyar Subjective WellBeing Questionnaire, and Goldberg and Hillier General Health Questionnaire were used to collect data. Data analyses were performed by applying a Pearson correlation coefficient and a stepwise regression analysis.

Results: This study revealed that negative feelings towards God and passive religious coping were related to subscales of general health among the mothers of mentally disabled children. The stepwise regression analysis demonstrated the most significant role of negative feelings towards God in predicting general health among the mothers of mentally disabled children. Moreover, none of the subscales of religious coping were able to predict the mothers' psychological well-being.

Discussion: The results of the current study suggest that the religious coping styles affect the general health among the mothers of mentally disabled children. This study also indicated that paying attention to the type of religious coping used by these mothers is essential.

\section{Introduction}

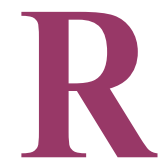

aising an independent child and creating healthy relations among family members are the primary responsibilities of a fam- ily, even if the child is mentally disabled [1]. The birth of a child with mental disability affects functions of family including psychological health, dynamism, purposefulness, conflict resolution, independence, development, moral and religious values, union, and control [2].

* Corresponding Author:

Zahra Nikmanesh, PhD

Address: Department of Psychology, Faculty of Education and Psychology, University of Sistan and Baluchestan, Zahedan, Iran.

Tel: +98 (915) 1404553

E-mail: zahranikmanesh@yahoo.com 
Numerous evidence shows that parents of children with psychological issues are more likely to encounter social, economic, and emotional problems [3]. Issues related to taking care of troubled children put parents at the risk of developing psychological problems [4, 5]. Mothers of mentally disabled children have lower levels of psychological health and psychological well-being and experience higher levels of anxiety, shame, and embarrassment in comparison with mothers of normal children [6]. Gupta indicated that the prevalence of depression among mothers of mentally disabled children and children with developmental disorders was higher than that among mothers of normal children [7]. Depression was one of the most common reactions among parents of mentally disabled children [7]. Emerson demonstrated that having a mentally disabled child reduced positive thinking and psychological health among mothers [8].

Gaining psychological health follows a process through which negative emotions such as anxiety, depression, and hopelessness are faded, and the onset of morbid symptoms is prevented [9]. Parents of mentally disabled children need help to identify, accept, and deal with the issues related to the [10]. Cummings et al. reported that mothers of the mentally disabled children dealt with high levels of anxiety and depression and experienced high levels of financial, emotional, and physical pressures. Additionally, the stress caused by economic, emotional, and physical issues were closely associated with low levels of mental health and psychological well-being of these mothers [11]. Romans-Clarkson et al. stated that mothers of mentally disabled children indicated more psychiatric symptoms than mothers of normal children and the conflicts in their marital relationships often led to a divorce [12]. Emerson reported decreased positive thinking and mental health among mothers of mentally disabled children [8].

Religion, as a unifying principle and a massive force, can be very useful for individuals' mental health [13]. Religious coping is defined as a method which applies religious resources, including prayer, and trust and appeals to God, to deal with stress [14]. Having a meaningful life, a sense of belonging to a divine source, and a sense of hopefulness are among sources which aid religious people to suffer less when faced with stressful life events [15].

Evidence indicates that religion and spirituality are closely correlated with mental health and psychological well-being. Kezday [16], Olsson [4], and Abbotts [17] indicated that external religion and negative religious coping (negative feelings towards God and passive religious coping) were correlated with depression and anxiety, fatigue, somatic complaints, and social dysfunctions. In contrary, being religious was associated with high levels of mental health and self-esteem and low aggression. The findings of Hebret [18] demonstrated significant positive correlations of negative religious coping with low mental health, depression, and satisfaction with life. Ismail [19] showed that there was a negative correlation between being religious and feelings of loneliness and anxiety.

The results of Trankle [20], Ellison et al. [21] showed significant positive correlations of religiosity with high levels of psychological well-being. Rew and Wong [22] reviewed that among 43 studies conducted to examine the association of religion with mental health, $84 \%$ of them reported a significant correlation between these two variables. McCullough and Larson reported that among 850 studies carried out to investigate the association between religion and mental health, two third of them found a significant positive relationship between practicing religious beliefs and mental health [23]. Chan and Rhodes [24] reported that there was a correlation between negative religious coping and psychological distress and there was an association between positive religious coping and posttraumatic growth. Chan et al., in another study, indicated that spirituality led to an increase in individuals' psychological well-being [25]. Also, people with an Islamic lifestyle are less susceptible to substance abuse [26].

The findings of Hayward and Krause [27] showed that religion/spirituality enhanced individual's psychological well-being. In contrast, Aldwin et al. [28] demonstrated that spirituality was firmly related to unhealthy behaviors (such as smoking and alcohol abuse). Da Silva et al. indicated that there was a significant and direct relationship between religion/spirituality and mental health [29]. Additionally, a study conducted by Freire and Moleiro [30] revealed that religion/spirituality was a powerful predictor of psychological and physical health. Moreover, Chirico [31] found that psychological and physical health can be improved and promoted by religion and spirituality.

Ghodrati et al. [32], Aghapour [33], and Shoakazemi [34] indicated that being religious was related to high levels of mental health and people who participated in more religious activities experienced low levels of aggression, anxiety, and depression. Bahrami et al. [35] demonstrated that coping styles, religious orientations, and personality dimensions can predict mental health.

Various studies are conducted on investigating positive effects of religion and spirituality on various aspects of health in different groups. However, studies on religious 
coping are scarce, and almost no studies are carried out to examine different effects of the positive and negative religious copings on mothers of mentally disabled children. The birth of a mentally disabled child is a critical stressful factor that can be accompanied by psychosocial consequences affecting people's quality of life such as anxiety, depression, concern about future, fatigue, physical constraints, and feelings of social isolation. It can has additional consequences that are very different for individuals involved. Therefore, studies should be conducted to recognize reasons for the effectiveness of psychological factors, so that, an effective step can be taken toward understanding and prevention of psychological harms. Considering the importance of religion and spirituality in psychological health, the present study was conducted to examine the role of religious coping styles in predicting general health and psychological well-being among mothers of mentally disabled children.

\section{Methods}

\section{Participants and procedure}

This was a cross-sectional study. The statistical population of the current study constituted of mothers $(n=68)$ of mentally disabled children who were studying in special schools in Zabol in the school year 2012-2013. The sample of this study selected using a convenience sampling method. Applying a random or nonrandom sampling method is sometimes difficult and/or even impossible in some cases. In such cases, a convenience sampling method is used. The convenience sampling method selects a group of members of the community just because of ease of sampling [36].

The subjects answered the questionnaires. Before filling the questionnaires, the aims of conducting the current study were explained to the mothers and those who were agree to participate in the study were asked to answer the questionnaires. The primary objectives and protocols of the study were explained to the participants. They were assured of the confidentiality of the collected information and freedom to withdraw from the study at any time. Informed consents were obtained from all the participants and questionnaires were distributed. Whenever a question seemed vague, some additional explanations were also provided. It should be noted that these explanations were provided to avoid any kinds of ambiguity and/or bias. Inclusion criteria were being $\geq 18$ years, having (at least) contradictory with an acceptable understanding of Persian language, and not dealing with any psychological disorders.

\section{Questionnaires}

\section{Religious Coping Scale}

Iranian Religious Coping Scale developed by Aflak Seir and Colman including five-point Likert-type items from zero (never) to four (always). Items of the scale are designed through applying Islamic texts and resources like Quran and Tradition as well as conducting interviews which provide information about Iranian Muslims' coping styles when dealing with pressure. It has two dimensions, i.e. positive religious coping and negative religious coping, and five subscales, i.e. religious activities, benevolent religious appraisal, active religious coping strategies (positive dimension), negative emotions toward God and passive religious coping strategies [37].

In a study conducted in Shiraz University students $(\mathrm{n}=185)$, the internal consistency of the scale for religious activities, benevolent appraisal, negative emotions toward God, passive coping and active coping, using Cronbach's alpha coefficient, respectively $0.89,0.79,0.79$. 0.72 , and $0.79[38]$. Moreover, in a study carried out on 238 women who took care of a sick family member, the reliability of the Religious Coping Scale was 0.79[36]. In this study, the Cronbach's alpha coefficient of this scale was 0.715 . In another study conducted on women with MS, the alpha coefficients of religious activities, benevolent appraisal, negative emotions toward God, passive religious coping strategies, and active religious coping were respectively $0.87,0.83,0.58,0.62$, and $0.67[39]$.

\section{General Health Questionnaire}

Goldberg and Hillier designed this 28-item questionnaire in 1979. Factor analysis of this questionnaire indicated four subscales of somatic symptoms, anxiety, social dysfunction, and depression, each including 7 items [40]. Hamid et al. [40] reported that the overall correlation coefficient of this questionnaire was 0.92 and the reliability of somatic symptoms, anxiety and insomnia, social dysfunction, and depression was $0.71,0.80,0.93$, and 0.73 , respectively. In addition, the convergent validity of this test with the SCL-90 was 0.87 [39]. The Cronbach's alpha coefficient of the General Health Questionnaire in this study was 0.81 . In a similar study, using the Cronbach's alpha coefficient, the reliability of all the subscales of this questionnaire ranged from 0.82 to 0.86 [41].

\section{Adolescent Subjective Well-Being Questionnaire}

Keyes and Magyar developed the Adolescent Subjective Well-being Questionnaire. This questionnaire 
includes three parts and evaluates emotional, psychological, and social dimensions of well-being [42]. Hashemian et al. [43] demonstrated that the correlation coefficients of the whole scale and its subscales, including emotional well-being, psychological well-being, and social well-being, were $0.78,0.76,0.64$, and 0.76 , respectively. Using the Cronbach's alpha coefficient, the internal consistency coefficient of the whole scale was obtained 0.80 and the internal consistency coefficient of emotional well-being, psychological well-being, and social well-being was $0.86,0.80$, and 0.61 , respectively. In the current study, the Cronbach's alpha coefficient of the Subjective Well-Being Questionnaire was 0.755. In Iran, the reliability and validity of this questionnaire were evaluated. Results of assessing its reliability using the test-retest method indicated that the reliability of the whole scale, emotional well-being, psychological wellbeing, and social well-being was $0.82,0.71,0.77$, and 0.78 , respectively [44]. The data analyses were conducted by applying the Pearson correlation coefficient and stepwise regression analysis via SPSS 16.

\section{Results}

The sample of this study included 68 mothers (aged 20-46 years) of mentally disabled children. Most of the mothers of mentally disabled children $(n=35,28 \%)$ were in the aged 29 to 37 years and the least number of the mothers of mentally disabled children $(n=12,9.6 \%)$ were aged 20 to 28 years. Regarding education level, $10.4 \%$ of these mothers were illiterate, $13.6 \%$ of them finished the elementary school, $13.6 \%$ of them finished the middle school, $11.2 \%$ of them had a diploma, and $5.6 \%$ of them had a degree higher than a diploma.

The means and standard deviations of the subjects' scores on religious coping styles, general health, and psychological well-being are presented in Table 1 . The results demonstrate that the highest mean relates to social well-being that is 64.58 .

Negative feelings towards God are significantly and positively related to anxiety $(\mathrm{P}<0.01)$ and depression $(\mathrm{P}<0.05)$ (Table 2). Moreover, passive coping is significantly and positively correlated with depression $(\mathrm{P}<0.01)$. This data show that the more a person uses negative coping (negative feelings towards God and passive coping), the lower his/her general health will be.

None of the subscales of religious coping are significantly related to emotional well-being, psychological well-being, and social well-being among the mothers of mentally disabled children (Table 3). Negative feelings towards God alone can explain 0.077 of the variance in general health among the mothers of mentally disabled children (Table 4). Beta coefficients (0.0301) show that a unit of change in negative feelings changes the general health among the mothers. Therefore, the variable

Table 1. The means and standard deviations of religious coping, general health, and psychological well-being

\begin{tabular}{|ccc}
\hline Variable & Mean & Standard Deviation \\
\hline Religious activities & 17.77 & 3.92 \\
\hline Negative feelings & 5.82 & 1.89 \\
\hline Benevolent appraisal & 15.44 & 2.4 \\
\hline Passive coping & 4.23 & 2.13 \\
\hline Active coping & 8.80 & 3.59 \\
\hline Somatic symptoms & 8.68 & 3.97 \\
\hline Anxiety and insomnia & 8.22 & 2.96 \\
\hline Social dysfunction & 7.86 & 2.82 \\
\hline Depression & 3.38 & 3.32 \\
\hline Emotional well-being & 38.82 & 64.12 \\
\hline Social well-being & 49.13 & 7.44 \\
\hline Psychological well-being & & 川ranian Rehabilitation Journal
\end{tabular}


Table 2. The results of the Pearson correlation coefficient between subscales of religious coping and general health among the mothers

\begin{tabular}{ccccc}
\hline & Somatic Symptoms & Anxiety & Social Dysfunction & Depression \\
\hline Religious activities & -0.102 & -0.177 & -0.126 & -0.189 \\
Negative feelings & 0.166 & $0.281^{* *}$ & 0.166 & $0.351^{*}$ \\
Benevolent reappraisal & 0.106 & 0.054 & 0.029 & -0.055 \\
Passive coping & 0.215 & 0.192 & 0.224 & $0.256^{* *}$ \\
\hline Active coping & 0.053 & 0.028 & -0.93 & -0.054 \\
\hline
\end{tabular}

Iranian Rehabilitation Journal

Table 3. The results of the Pearson correlation coefficient between subscales of religious coping and psychological well-being among the mothers

\begin{tabular}{cccc}
\hline & Emotional Well-Being & Psychological Well-Being & Social Well-Being \\
\hline Religious activities & 0.121 & -0.159 & -0.017 \\
Negative feelings & -0.098 & 0.188 & 0.004 \\
Benevolent reappraisal & -0.008 & -0.228 & -0.154 \\
Passive coping & -0.80 & 0.129 & -0.177 \\
\hline Active coping & -0.069 & -0.086 & -0.140 \\
\hline
\end{tabular}

Iranian Rehabilitation Journal

of negative feelings (Beta coefficients $=0.301, \mathrm{P}<0.05$ ) is a predictor of general health among the mothers of mentally disabled children.

\section{Discussion}

In the current cross-sectional study, data showed that negative feelings towards God were significantly and positively related to anxiety and depression. Moreover, passive coping was significantly and positively correlated with depression. This data reveals that a person with negative coping (negative feelings towards God and passive coping) has lower general health. The results indicated that none of the subscales of religious coping were significantly related to emotional well-being, psychological well-being, and social well-being among the mothers of mentally disabled children. Moreover, the results of regression analysis indicated that negative religious feelings had the most significant impact on the mothers' general health. The obtained findings are consistent with the results of several studies which demonstrated that the mothers of mentally disabled children had low general health and experienced high levels of anxiety and depression $[4,16,35]$.

Kezday [16], Olsson [4], and Abbotts [45] reported that external religion and negative religious coping (negative feelings towards God and passive religious coping) were correlated with depression and anxiety, fatigue, somatic complaints, and social dysfunctions. On the other hand, being religious was associated with high levels of mental health and self-esteem and low aggression. Similarly, Hebret [18] showed significant positive correlations of negative religious coping with low mental health, depression, and satisfaction with life. Moreover, Ismail [19]

Table 4. The results of stepwise regression analysis conducted to predict general health via subscales of religious coping

\begin{tabular}{|c|c|c|c|c|c|c|c|c|}
\hline & $\mathbf{R}$ & Adjusted R & B & SD & Beta & $\mathbf{T}$ & $\mathbf{F}$ & Sig. \\
\hline & & & 18.32 & & & 4.56 & & \\
\hline Negative feelings & 0.301 & 0.077 & 1.68 & 4.014 & 0.301 & 2.56 & 6.57 & 0.013 \\
\hline
\end{tabular}


revealed that there was a negative correlation between being religious and feelings of loneliness and anxiety.

Chan and Rhodes [24] showed that there was an association between adverse religious coping and psychological distress and there was a correlation between positive religious coping and posttraumatic growth. Another study conducted by Chan et al. reported that spirituality led to an increase in individuals' psychological well-being [25].Moreover, Aldwin et al. [28] demonstrated that spirituality was closely related to unhealthy behaviors (such as smoking and alcohol abuse). Also, the findings of Hayward and Krause [27] showed that religion/spirituality enhanced individual's psychological well-being. Da Silva et al. indicated that religion/spirituality was significantly and directly related to psychological health. Additionally, the results of a study conducted by Freire and Moleiro [30] revealed that religion/spirituality was a powerful predictor of psychological and physical health. Moreover, Chirico [31] found that religion and spirituality can improve and promote individuals' psychological and physical health.

Ghodrati et al. [32], Aghapour [33], and Shoakazemi [34] reported that being religious was related to better mental health and people who participated in more religious activities experienced lower levels of aggression, anxiety, and depression. Bahrami et al. [35] demonstrated that coping styles, religious orientations, and personality dimensions were all able to predict mental health among mothers of mentally disabled children.

Negative religious coping, such as resentment and anger towards God, doubt about beliefs, and questioning religious faith, can effect negativly on the health of mothers who have mentally disabled children. Mothers' resentment towards God rooted in the fact that their children are mentally disabled or their anger towards God stemmed from the fact that they have to spend their lives taking care of their disabled children makes mothers vulnerable to the application of ineffective coping strategies and can be considered as a predictor of anxiety and depression. Therefore, believing in God, who controls all situations and governs people, greatly reduces anxiety, such that most faithful people describe their relationship with God as a close one and believe that they can manage uncontrollable situations through relying on and trusting in God.

The limitations of the present study were the small sample size, the unwillingness to participate due to poor physical and mental conditions, and the low literacy or illiteracy of some of the participants (solved through reading questionnaires by the researcher). Therefore, to compare the effects of cultural, religious, and genderrelated factors on general health, future studies on larger samples can be conducted., Furthermore, other variables influencing general health, subjects with different cultural backgrounds and religious beliefs, and both parents of mentally disabled children should be taken in account for future studies.

\section{Conclusion}

It can be concluded that religious coping styles are predictors of general health in mothers of mentally disabled children. Additionally, positive religious coping styles relying on religious beliefs and activities help individuals who believe in religion to have a positive appraisal of life events and suffer from fewer traumas when faced with stressful events. Thus, religious coping can be considered as a strategy to create a positive reaction to traumatic events, develop general health, and improve quality of life. Therefore, it is highly recommended that institutes and centers which deal with parents of mentally disabled children pay more attention to these people's religious coping styles and present related training and cultural programs aiming at promoting parents' positive religious coping.

\section{Acknowledgments}

This article is based on the MA thesis of Hadi Ansari in Islamic Azad University, Zahedan Branch, Iran. We greatly appreciate all participants' cooperation.

\section{Conflict of Interest}

The authors declare no conflicts of interest.

\section{References}

[1] Motamedin M SF, Fathiazar E, Maleki S. [The comparison of mental health, marriage satisfaction and assertiveness between parents of mental retarded and normal (girl and boy) of primary school's student in West Azerbaijan (Persian)] Knowledge \& Research in Applied Psychology. 2009; 10(3536):123-52.

[2] Kimiyaie SA, Meh Abadi H, Mirzaee Z. [Comparing the mental health of parents with educable mentally retarded children in Mashhad (Persian)]. Studies in Education and Psychology. 2010; 11(1):278-61.

[3] Khamis V. Psychological distress among parents of children with mental retardation in the United Arab Emirates. 
Social Science \& Medicine. 2007; 64(4):850-7. Available from: http:/ /dx.doi.org/10.1016/j.socscimed.2006.10.022

[4] Olsson MB, Hwang CP. Depression in mothers and fathers of children with intellectual disability. Journal of Intellectual Disability Research. 2001; 45(6):535-43. Available from: http:/ /dx.doi.org/10.1046/j.1365-2788.2001.00372.x

[5] McConkey R, Truesdale-Kennedy M, Chang MY, Jarrah S, Shukri R. The impact on mothers of bringing up a child with intellectual disabilities: A cross-cultural study. International Journal of Nursing Studies. 2008; 45(1):65-74. Available from: http:/ / dx.doi.org/10.1016/j.ijnurstu.2006.08.007

[6] Michaeli Manee F. [A comparative study on psychologica well-being in mothers of elementary students with and without intellectual disabilities (Persian)]. Journal of Exceptional Children. 2008; 8(1):53-69.

[7] Ashum G, Singhal N. Positive perceptions in parents of children with disabilities. Asia Pacific Disability Rehabilitation Journal. 2004; 15(1):22-34

[8] Emerson E. Mothers of children and adolescents with intellectual disability: social and economic situation, mental health status, and the self-assessed social and psychological impact of the child's difficulties . Journal of Intellectual Disability Research. 2003; 47(4):385-99. doi: 10.1046/j.13652788.2003.00498.x

[9] World Health Organization. Mental health: strengthening mental health promotion. Geneva: World Health Organization; 2007.

[10] Hosseini SH, Rezazadeh H. [Comparative study on psycho- social needs of mental restarted, thalassemia and normal primary boy students' parents in Sari Township (Persian)]. Journal of Mazandaran University of Medical Sciences. 2002; 12(37):28-34.

[11] Cummings T, Bayley HC, Rie HE. Effects of the child's deficiency on the mother: A study of mothers of mentally retarded, chronically ill and neurotic children. American Journal of Orthopsychiatry. 1966; 36(4):595-698. doi: 10.1111/j.19390025.1966.tb02311.x

[12] Romans-Clarkson SE, Clarkson JE, Dittmer ID, Flett R, Linsell C, Mullen PE, et al. Impact of a handicapped child on mental health of parents. BMJ. 1986; 293(6559):1395-7. Available from: http:/ / dx.doi.org/10.1136/bmj.293.6559.1395

[13] Maddahi ME, Samadzaade M, Keikhayfarzaneh MM. [The relationship between religious orientation and psychological well-being among university students (Persian)]. Educational Psychology. 2011; 2(1):53-63.

[14] Billings AG, Moos RH. Coping stress and social resources among with unipolar depression. Journal of Personality and Social Psychology. 1984; 46(4):877-91. PMID: 6737198

[15] Fathi M. [Intimate letters with MS Patients (Persian)]. Tehran: Shahid Poor; 2010

[16] Kézdy A, Martos T, Boland V, Horváth-Szabó K. Religious doubts and mental health in adolescence and young adulthood: The association with religious attitudes. Journal of Adolescence. 2011; 34(1):39-47. Available from: http://dx.doi. org/10.1016/j.adolescence.2010.03.003

[17] Abbotts JE, Williams RG., Sweeting HN, West PB. Is going to church good or bad for you? Denomination, attendance and mental health of children in West Scotland. Social Science \& Medicine. 2004; 58(3):645-56. Available from: http:/ / dx.doi.org/10.1016/s0277-9536(03)00283-1

[18] Hebert R, Zdaniuk B, Schulz R, Scheier M. Positive and Negative Religious Coping and Well-Being in Women with Breast Cancer. Journal of Palliative Medicine. 2009; 12(6):53745. Available from: http:/ / dx.doi.org/10.1089/jpm.2008.0250

[19] Ismail Z, Desmukh S. Religiosity and Psychological WellBeing. International Journal of Business and Social Science. 2012; 3(11):102-16.

[20] Trankle T. Psychological Well-Being, Religious Coping, and Religiosity in College Students. Journal for the Scientific Study of Religion. 2003; 17:29-33.

[21] Ellison CG, Boardman JD, Williams DR, Jackson JS. Religious Involvement, Stress, and Mental Health: Findings from the 1995 Detroit Area Study. Social Forces. 2001; 80(1):215-49. Available from: http:/ /dx.doi.org/10.1353/sof.2001.0063

[22] Rew L, Wong YJ. A systematic review of associations among religiosity/spirituality and adolescent health attitudes and behaviors. Journal of Adolescent Health. 2006 38(4):433-42. Available from: http://dx.doi.org/10.1016/j. jadohealth.2005.02.004

[23] King PE, Roeser RW. The role of religion and spirituality in adolescents' lives, demographic trends. In: King PE, Roeser RW, editor. Handbook of Adolescent Psychology. New York: Wiley-Blackwell; 2009.

[24] Chan CS, Rhodes JE. Religious Coping, Posttraumatic Stress, Psychological Distress, and Posttraumatic Growth Among Female Survivors Four Years After Hurricane Katrina. Journal of Traumatic Stress. 2013; 26(2):257-65. Available from: http:/ /dx.doi.org/10.1002/jts.21801

[25] Ivtzan I, Chan CPL, Gardner HE, Prashar K. Linking Religion and Spirituality with Psychological Well-being: Examining Self-actualisation, Meaning in Life, and Personal Growth Initiative. Journal of Religion and Health [Internet]. Springer Nature; 2011; 52(3):915-29. Available from: http://dx.doi. org/10.1007/s10943-011-9540-2

[26] Padarvand A, Kalantarkousheh SM, Doostian Y, Massah $\mathrm{O}$, Varmazyar HR, Arian M. The association between Islamic lifestyle and addiction potential among adolescents. Journal of Practice in Clinical Psychology. 2017; 5(1):27-32. doi 10.18869/acadpub.jpcp.5.1.27

[27] Hayward RD, Krause N. Religion, mental health and wellbeing: Social aspects. In: V. Saroglou editor. Religion, Personality, and Social Behavior. 2014. New York: Psychology Press.

[28] Aldwin CM, Park CL, Jeong YJ, Nath R. Differing pathways between religiousness, spirituality, and health: A self-regulation perspective. Psychology of Religion and Spirituality. 2014; 6(1):9-21. Available from: http://dx.doi.org/10.1037/ a0034416

[29] Da Silva AF, de Carvalho Ferreira, de Macêdo Melo R, Lúcia Cruz Caldas Lins H, Natércia Soares Feitosa U, Antonio de Araújo Neto E, dos Santos Rocha S, Leite Rolim Neto M. The influence of religiosity/spirituality on mental health. International Archives of Medicine. 2015; 8(116):1-4. doi: $10.3823 / 1715$

[30] Freire J, Moleiro C. Religiosity, Spirituality, and Menta Health in Portugal: a call for a conceptualization, relation- 
ship, and guidelines for integration (a theoretical review). Revista Psychologies. 2016; 29(2):17-32. doi: 10.17575/rpsicol v29i2.1006

[31] Chirico F. Spiritual well-being in the 21st century: it's time to review the current WHO's health definition? Journal of Health and Social Sciences. 2016; 1(1):11-6.

[32] Maleki Z, Ashkan S, Ashoori J, Yosefi N. Relationship between personality traits, religiosity and happiness with general health among nursing students. Iran Journal of Nursing. 2013; 26(86):90-100.

[33] Yeganeh T. [The role of religious orientation in determining hope and psychological well-being of women diagnosed with breast cancer (Persian)]. Journal of Breast Diseases. 2014; 6(3):47-56.

[34] García-Alandete J, Bernabé-Valero G. [Religious orientation and psychological well-being among Spanish undergraduates (Spanish)]. Acción Psicológica. 2013; 10(1):135-148. Available from: http:/ / dx.doi.org/10.5944/ap.10.1.7040

[35] Sadri Damirchi E, Mohammadi N, Fayazi M, Afsar E. [Examining the relationship of psychological well-being with religious orientation and forgiveness among students at the University of Mohaghegh Ardabili (Persian)]. Journal of Research on Religion \& Health. 2017; 3(2):20- 30.

[36] Hasanzade R. [Research methods in behavioral sciences (Persian)]. Tehran: Savalan; 2010.

[37] Aflakseir A. Initial development of the Iranian religious coping scale. Journal of Muslim Mental Health. 2011; 6(1):4461. doi: $10.3998 / j m m h .10381607 .0006 .104$

[38] Nikmanesh Z, Parandeh L, Abtahi SHR, Sepehrnejad M, Nilforoush MH. The religious coping and quality of life in mothers of children with hearing deficiency. Iranian Rehabilitation Journal. 2015; 13(3):113-8.

[39] Askari N, Nikmanesh Z. The role of religious coping in predicting quality of life in patients with Multiple Sclerosis. Armaghane Danesh. 2014; 19 (5):470-479.

[40] Hamid N, Golestanipoor M, Karin Nezhad. [Simple and multiple relationships religious identity, mental health and optimism (Persian)]. Ravanshenasi va Din. 2002; 6(1):77-90.

[41] Mir Arab R, Azizi A, Moradi M. [Anticipate of relationship between mental health and performance of job based on personality characteristic of Noshahr naval military personnel (Persian)]. Quarterly Journal of Management of Marine Science Education. 2014; 1(1):48-60.

[42] Keyes CLM, Magyar-Moe JL. The measurement and utility of adult subjective well-being. In: Snyder CR editor. Positive Psychological Assessment: A Handbook of Models and Measures. New York: American Psychological Association. Available from: http://dx.doi.org/10.1037/10612-026

[43] Hashemiyan K, Pour Shahriari MS, Bani Jamali SS, Golestani Bakht T. [The relationship between demographic characteristics and degree of - bio mind and happiness in Tehran. Quarterly Journal of Psychological Studies. 2007; 3(3):139-63.

[44] Bayani AA, Mohammad Koochekya A, Bayani A. [Reliability and validity of Ryff's Psychological Well-being Scales (Persian)]. Iranian Journal of Psychiatry and Clinical Psychology. $2008 ; 14(2): 146-151$
[45] Abbotts JE, Williams RG, Sweeting HN, West PB. Is going to church good or bad for you? Denomination, attendance and mental health of children in West Scotland. Social Science \& Medicine. 2004; 58(3):645-56. Available from: http:// dx.doi.org/10.1016/s0277-9536(03)00283-1 